\title{
Geotecnologias em perícias ambientais: aplicabilidade para estudos em represas de abastecimento e áreas protegidas
}

A qualificação dos danos ambientais depende do seu perfeito enquadramento aos estritos termos da legislação ambiental vigente e a comprovação de sua materialidade é indispensável $n$ responsabilização dos autores. A comprovação da materialidade dos danos ambientais, em alguns casos, pode ser uma atividade bastante complexa, pois, quando não há uma prova pericial contundente acerca de sua existência, o autor do dano pode ser absolvido. Nesse âmbito, as geotecnologias surgem como ferramentas para auxiliar os trabalhos periciais, facilitando a comprovação da materialidade dos danos ambientais e permitindo análises qualitativas e quantitativas acerca da evolução dos danos ambientais causados pelo desmatamento e/ou expansão urbana na paisagem examinada. Assim, o presente trabalho visou sistematizar uma metodologia para produção de provas periciais a partir da utilização das geotecnologias - tais como Sensoriamento Remoto, Sistemas de Informações Geográficas, Sistema de Navegação Global por Satélite, Métricas da Paisagem, dentre outras - em perícias ambientais de identificação e Sensoriamento Remoto, Sistemas de Informações Geográficas, Sistema de Navegação Global por Satélite, Métricas da Paisagem, dentre outras - em perícias ambientais de identificação e reservatório de abastecimento de água para a Região Metropolitana de Belo Horizonte, Minas Gerais. Foram utilizados dados oficiais e informações espaciais obtidos gratuitamente em plataformas online, como o Geo Catálogo do Ministério do Meio Ambiente, o IDE Sisema, do Sistema Estadual de Meio Ambiente e Recursos Hídricos de Minas Gerais, e o MapBiomas. Também foram utilizados dados coletados em campo. O processamento e a análise dos dados se realizaram por meio dos softwares gratuitos QGIS 3.8, Google Earth e Dinâmica EGO 4.2. Os resultados da metodologia proposta foram apresentados e discutidos de forma qualitativa e quantitativa no que se refere ao emprego das diferentes soluções de geotecnologia dentro do escopo do processo pericial. Essa metodologia se valeu de técnicas de inspeção visual para abordar os aspectos qualitativos da identificação de possíveis danos ambientais, e de técnicas quantitativas de sensoriamento remoto que possibilitaram a mensuração de métricas para comprovação da infração ambiental, bem como a mensuração das transformações ocorridas na paisagem durante um período anterior e após a infração. Os danos ambientais observados foram identificados de maneira simples, direta e persuasiva, esses resultados não só ratificam o alto poder elucidativo das informações espaciais em perícias ambientais, demonstrando que as geotecnologias propiciam melhores condições para entender a problemática, como também auxiliam importantes decisões no que concerne a esse tipo de perícia.

Palavras-chave: Perícia ambiental; Fiscalização ambiental; Geotecnologias; Abastecimento de água.

\section{Geotechnologies in environmental expertise: applicability for studies in supply dams and protected areas}

The qualification of environmental damage depends on its perfect compliance with the terms of the environmental legislation in use. Proofing the materiality of the environmental damages is indispensable to sign the responsibility of the authors. In some cases, this proof can be very a complex task when strong pieces of evidence about its existence of the environmental impact are missing. Thus, the perpetrator of the damage can be acquitted. Given the needs for best assist the environmental expert, geotechnologies emerge as data, tools, and methods capable of facilitating the verification of the materiality of the damage. They allow qualitative and quantitative analysis of the environmental impact on the landscape either caused by deforestation and/or urban expansion. In this investigation, we present a systematic approach for producing expert pieces of evidence of environmental damage, its identification and quantification of the harm using geotechnologies such as Remote Sensing, Geographic Information Systems, Global Satellite Navigation System, Landscape Metrics. The Environmental Protection Area of data collected in the field. As for the tools, the methodology was designed to use free software such as QGIS 3.8, Dinamica-EGO and Google Earth. The investigation produced qualitative and quantitative results regarding the geotechnology solutions used within the scope of the expert process. At first, the methodological approach relied on visual inspection techniques to addres the qualitative aspects of the identification of possible environmental damage. Then, quantitative remote sensing techniques were used to capture metrics related to the characterization and proof of the environmental violation. Quantitative methods were also used to measure the dynamics of the landcover changes occurred in the landscape during the previous period and after the infringement. The environmental damages were identified in a simple, direct and persuasive way. Findings not only ratify the high explanatory power of spatial information for environmental judicial but also help important decisions in what concerns to that kind of expertise.

Keywords: Environmental expert; Environmental enforcement; Geotechnologies; Water supply.

Topic: Tecnologia, Modelagem e Geoprocessamento

Reviewed anonymously in the process of blind peer.

Marcos de Paulo Ramos (id

Instituto Federal de Minas Gerais, Brasil http://lattes.cnpq.br/6704718932869954 http://orcid.org/0000-0003-3296-6590

marcosramos.ufv@gmail.com

Rodrigo Affonso de Albuquerque Nóbrega

Universidade Federal de Minas Gerais, Brasil

http://lattes.cnpq.br/7158751194696023

http://orcid.org/0000-0001-7058-5903

raanobrega@ufmg.br
Received: 11/03/2020

Approved: 22/04/2020
Referencing this:

RAMOS, M. P.; NÓBRIGA, R. A. A.. Geotecnologias em perícias ambientais: aplicabilidade para estudos em represas de abastecimento e áreas protegidas. Revista Ibero Americana de Ciências Ambientais, v.11, n.3, p.469-484, 2020. DOI: 


\section{INTRODUÇÃO}

A crescente conscientização sobre a necessidade de repensar nossa relação com o planeta tem se refletido em mudanças de comportamento e na elaboração de ordenamentos jurídicos cada vez mais complexos, que visam reparar erros passados e prevenir futuros (LIMA, 2013). Nesse sentido, condutas e atividades consideradas lesivas ao meio ambiente sujeitarão os infratores, pessoas físicas ou jurídicas, às sanções administrativas, sem prejuízo das obrigações de reparar o dano e das cominações penais cabíveis.

Tendo identificado o dano ambiental e as condutas e/ou atividades lesivas ao meio ambiente, a legislação vigente prevê sanções administrativas, cíveis e penais no que refere à questão cível (reparação do dano) e, para tanto, a tipificação da atividade e da conduta lesiva pela legislação exige que a comprovação de sua materialidade seja realizada pela perícia ambiental, que é o instrumento jurídico para identificar e mensurar os danos, os autores e embasar as medidas mitigadoras que vierem a ser determinadas aos infratores (BENEDET et al., 2016).

A qualificação dos danos ambientais, depende do seu perfeito enquadramento aos estritos termos da legislação ambiental vigente, bem como a comprovação de sua materialidade, é indispensável para a responsabilização dos autores. A comprovação da materialidade dos danos, em alguns casos, pode ser uma atividade bastante complexa, posto que demanda análises rápidas, abrangentes, transparentes e precisas. Porém, em muitos casos, a perícia ambiental se restringe a coletar coordenadas dos pontos examinados e a produzir relatórios fotográficos. Como consequência, não são produzidos e anexados aos autos processuais materiais cartográficos complementares que poderiam melhor caracterizar os danos ambientais. Assim, quando não há provas periciais contundentes, o autor do dano pode ser absolvido.

Considerando-se as peculiaridades dos tipos de danos ambientais previstos pela legislação, a comprovação de sua materialidade requer utilização de técnicas específicas, dentre as quais se destacam as geotecnologias, tais como o Sensoriamento Remoto, os Sistemas de Informações Geográficas (SIG), o Veículo Aéreo Não Tripulado (VANT), o Sistema de Navegação Global por Satélite (GNSS) e as Métricas da Paisagem, dentre outros recursos (BRILIS et al., 2000a; BRILIS et al., 2000b; CALDAS et al., 2009; ALVES et al., 2011; GASPARINI et al., 2013; LIMA, 2013; SILVA et al., 2013; ARAGÃO et al., 2014; BOEIRA et al., 2015; NICOLETTI et al., 2015; SILVA et al., 2015). O uso das geotecnologias aliado à utilização de produtos cartográficos existentes (ortofotos, imagens de satélites, cartas, mapas etc.) permite que se realizem levantamentos prévios de informações relativas à área a ser periciada, tornando os trabalhos de campo mais objetivos e eficientes (CALDAS et al., 2009). Além disso, durante os trabalhos periciais, o perito pode se valer das geotecnologias com a finalidade de comprovar a materialidade do dano ambiental e, como consequência, proporcionar a perfeita elucidação do caso, uma vez que a apresentar a documentação espacial pode ser uma maneira simples, direta, persuasiva e contundente de identificar ou eliminar partes potencialmente responsáveis em ações de fiscalizações e perícias (BRILIS et al., 2000a).

Contudo, o emprego prático de imagens oriundas do sensoriamento remoto para fins cartográficos requer a utilização de técnicas de Processamento Digital de Imagens (PDI), que podem ser entendidas como 
um conjunto de estratégias para a manipulação de imagens digitais as quais facilitam a extração de informações e corrigem eventuais erros e distorções (IBGE, 2001). Cabe ressaltar, porém, que se deve evitar o manuseio dessas tecnologias sem o devido cuidado, pois imagens não tratadas adequadamente apresentam distorções que podem inviabilizar sua utilização cartográfica e/ou pericial (LIMA, 2013).

Nesse sentido, esta pesquisa visou demonstrar a viabilidade do emprego de geotecnologias para aprimoramento do processo de perícia ambiental. Para tanto, foram traçados os seguintes objetivos específicos: Revelar as lacunas e as principais demandas por soluções de geotecnologia no apoio às atividades de perícia ambiental; Desenvolver um estudo de caso, aplicando diferentes soluções de geoprocessamento no apoio à perícia ambiental; Analisar, de forma qualitativa e quantitativa, os resultados do emprego das diferentes soluções de geotecnologia dentro do escopo do processo pericial; Elencar as vantagens, as desvantagens, as mudanças de paradigma e os desafios de sua utilização.

Visando ao melhor desempenho no desenvolvimento da pesquisa, tornou-se necessário eleger duas importantes estratégias: [1] selecionar uma área de estudo que contemplasse casos complexos reais de danos ambientais, com ações e perícias judiciais em curso, para avaliações in loco do potencial e da viabilidade do emprego de geotecnologia; e [2] considerar a existência e a disponibilidade de dados geográficos, referentes à área de estudo, passíveis de serem empregados para o propósito da pesquisa.

\section{REVISÃO TEÓRICA}

\section{Área De Estudo}

Com base nas estratégias supracitadas, a Área de Proteção Ambiental (APA) de Vargem das Flores foi selecionada como área de estudo. Essa área corresponde a uma unidade de conservação de uso sustentável, com 12.268,00 ha, onde está situada a represa denominada Várzea das Flores, a qual configura um importante reservatório de abastecimento de água para os municípios de Betim, Contagem e Belo Horizonte, e faz parte da sub-bacia do Rio Paraopeba, afluente do Rio São Francisco. A APA Vargem das Flores, criada pela Lei Estadual no 16.197/2006, está localizada nos municípios de Betim/MG e Contagem/MG, fazendo divisa com os municípios de Esmeraldas/MG e Ribeirão das Neves/MG. Pela sua beleza natural e proximidade com a capital do Estado e região metropolitana, tem sido utilizado pela população do entorno como área de lazer para pesca e banhos, bem como para especulação imobiliária (FIGURA 1).

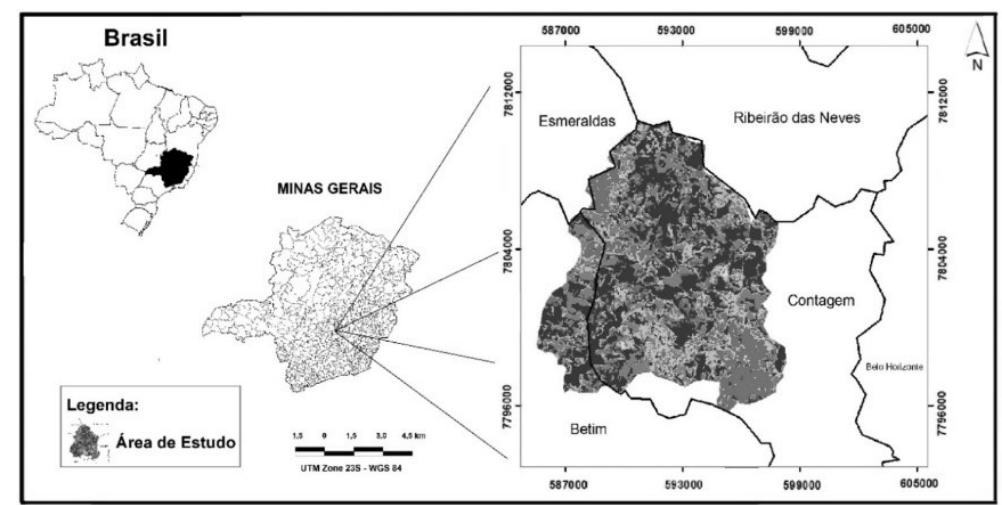

Figura 1: Área de estudo. 
No entorno da represa é notório observar o conflito de uso do solo, que vem se configurando não só pela supressão da cobertura vegetal mais densa como também pela introdução acelerada de edificações e de infraestrutura viária. Em junho de 2015, por causa da pressão antrópica na paisagem, a Subsecretaria de Controle e Fiscalização Ambiental Integrada da Secretaria de Estado de Meio Ambiente e Desenvolvimento Sustentável (SEMAD) instaurou uma fiscalização na região de Vargem das Flores, ou seja, na área que compreende a represa Várzea das Flores e o seu entorno. A operação foi realizada com intuito de coibir ações predatórias ao meio ambiente e verificar a regularidade dos empreendimentos localizados nessa região. Com base nos resultados da fiscalização, o Estado de Minas Gerais propôs, em desfavor dos fiscalizados, uma Ação Civil Pública (ACP).

O exame proposto utilizou geotecnologias para apoiarem a operacionalização do processo de fiscalização, mesmo ciente de que a metodologia e os produtos por ela gerados carecem de protocolos de uso para essa finalidade, como, por exemplo, a especificação dos dados, dos equipamentos e das ferramentas para perícia ambiental.

\section{Recursos Materiais}

Assim como a seleção da área de estudo, a seleção dos recursos materiais foi de fundamental importância para a proposta metodológica desta pesquisa. Não apenas a existência e a disponibilidade dos dados foram levadas em consideração, mas também a adequação desses dados para o escopo da investigação proposta, tais como a demanda da resolução espacial e temporal das imagens disponíveis.

Os recursos materiais, computacionais e equipamentos utilizados durante a realização dos estudos, foram um receptor GPS de navegação (Garmin 62S), uma trena digital laser (Bosch DLE 70 Professional), uma trena de fibra de vidro 50 m, softwares gratuitos QGIS 3.8 e Dinâmica EGO 4.2, um tablet, um computador pessoal e a base cartográfica digital da área de estudo (Quadro 1).

Embora seja indiscutível a notória qualidade dos dados geográficos de fontes privadas e haja uma diversidade de sistemas de geoprocessamento disponíveis, muitos deles tradicionais e com recursos capazes de atender à demanda da pesquisa, utilizamos, em nossa investigação - em virtude da natureza da proposta, apenas ferramentas livres e dados públicos de órgãos oficiais. Acreditamos que essas medidas podem contribuir para a desmistificação e a disseminação do geoprocessamento enquanto suporte a operações de perícia e à tomada de decisões judiciais.

Quadro 1: Informações gerais sobre a fonte de dados utilizada.

\begin{tabular}{|c|c|c|c|}
\hline Abreviação & Nome & Informações gerais & Dados utilizados \\
\hline IDE-Sisema $^{1}$ & $\begin{array}{l}\text { Infraestrutura de Dados } \\
\text { Espaciais do Sistema } \\
\text { Estadual de Meio } \\
\text { Ambiente e Recursos } \\
\text { Hídricos }\end{array}$ & $\begin{array}{l}\text { - Plataforma criada pelo Sistema Estadual de Meio } \\
\text { Ambiente e Recursos Hídricos de Minas Gerais } \\
\text { (Sisema); } \\
\text { - Permite o download gratuito nos formatos kml e } \\
\text { shapefile; } \\
\text { - Abrangência: estado de Minas Gerais. }\end{array}$ & $\begin{array}{l}\text { - Limites municipais; } \\
\text { - Limites do reservatório; } \\
\text { - Perímetro da APA; } \\
\text { - Hidrografia e outros. }\end{array}$ \\
\hline MapBiomas ${ }^{2}$ & Projeto de Mapeamento & - Processamento em nuvem; & - Mapas de uso e \\
\hline
\end{tabular}

${ }^{1}$ http://idesisema.meioambiente.mg.gov.br

2 http://plataforma.mapbiomas.org 


\begin{tabular}{|c|c|c|c|}
\hline & $\begin{array}{l}\text { Anual da Cobertura e } \\
\text { Uso do Solo do Brasil }\end{array}$ & $\begin{array}{l}\text { - Classificadores automatizados desenvolvidos e } \\
\text { operados na plataforma Google Earth Engine; } \\
\text { - Mapas anuais de cobertura e uso da terra do } \\
\text { Brasil; } \\
\text { - Rede colaborativa com especialistas de diversas } \\
\text { áreas. }\end{array}$ & $\begin{array}{l}\text { cobertura do solo para os } \\
\text { anos de } 1996 \text { e } 2016 \text {, com } \\
\text { resolução de } 30 \mathrm{~m} \text {. }\end{array}$ \\
\hline $\begin{array}{l}\text { Geo Catálogo } \\
\mathrm{MMA}^{3}\end{array}$ & $\begin{array}{l}\text { Catálogo de Imagens de } \\
\text { Satélite Rapideye do } \\
\text { Ministério do Meio } \\
\text { Ambiente (MMA) }\end{array}$ & $\begin{array}{l}\text { - Imagens utilizadas e disponibilizadas para apoiar } \\
\text { o Programa de Regularização Ambiental; } \\
\text { - Acessíveis a todos os órgãos públicos federais, } \\
\text { estaduais, municipais e universidades públicas; } \\
\text { - Resoluções: } 5 \text { m (espacial); } 12 \text { bits } \\
\text { (radiométrica), } 5 \text { faixas (espectral) e } 24 \text { horas off- } \\
\text { nadir (temporal). }\end{array}$ & $\begin{array}{l}\text { - Duas cenas } \\
\text { identificadoras: } \\
2329918 \text { e } 2329919 \text { (2014- } \\
09 \text { 12_RE3_3A_312511). }\end{array}$ \\
\hline Google Earth & $\begin{array}{l}\text { Aplicativo de mapas } \\
\text { mantido pelo Google }\end{array}$ & $\begin{array}{l}\text { - Permite visualizar gratuitamente, de forma } \\
\text { virtual, de qualquer lugar do planeta; } \\
\text { - Imagens orbitais e aéreas obtidas por diferentes } \\
\text { sensores; } \\
\text { - Imagens disponíveis na composição colorida RGB } \\
\text { comum. }\end{array}$ & $\begin{array}{l}\text { - Cinco imagens de } \\
\text { diferentes datas. }\end{array}$ \\
\hline $\begin{array}{l}\text { Fotografias } \\
\text { Aéreas } \\
\text { Ortorretificadas }\end{array}$ & $\begin{array}{l}\text { Ortofoto adquirida pela } \\
\text { Prefeitura de } \\
\text { Contagem/MG }\end{array}$ & $\begin{array}{l}\text { - Levantamento aerofotogramétrico realizado sob } \\
\text { demanda; } \\
\text { - Voo realizado em 2017; } \\
\text { - Resolução Espacial: 0,10 m; } \\
\text { Acesso: Disponibilizado em mídia física pela } \\
\text { secretaria municipal de Planejamento (SEPLAN). }\end{array}$ & $\begin{array}{l}\text { - Recorte da área da APA } \\
\text { localizada em } \\
\text { Contagem/MG. }\end{array}$ \\
\hline
\end{tabular}

\section{METODOLOGIA}

\section{Proposta Metodológica}

A metodologia utilizada neste estudo é uma sequência de análises exploratórias de diferentes soluções de geotecnologias aplicadas à perícias ambientais e teve como base o que foi proposto em investigações semelhantes por diversos autores (BRILIS et al., 2000a; BRILIS et al., 2000b; CALDAS et al., 2009; ALVES et al., 2011; GASPARINI et al., 2013; LIMA, 2013; SILVA et al., 2013; ARAGÃO et al., 2014; BOEIRA et al., 2015; NICOLETTI et al., 2015; SILVA et al., 2015), no intuito de encontrarmos formas de criar protocolos de emprego dessas técnicas e instrumentos. A Figura 2, mostra esquema, ilustrando o roteiro metodológico e as etapas da pesquisa.

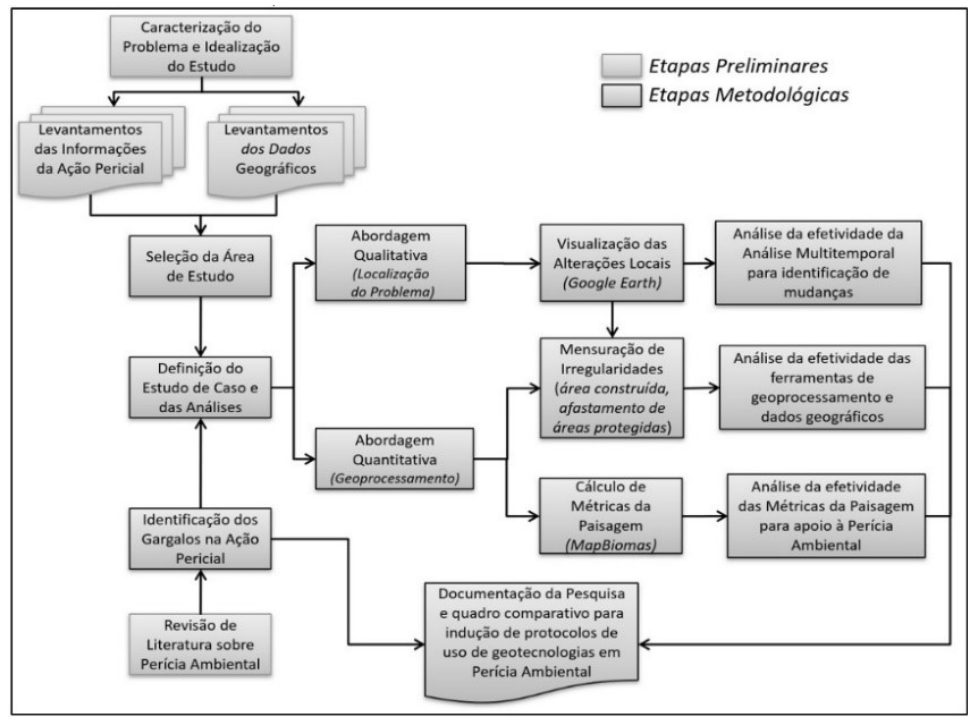

Figura 2: Metodologia proposta.

\footnotetext{
${ }^{3}$ http://geocatalogo.mma.gov.br
} 


\section{Identificação dos gargalos da ação pericial}

Não é difícil encontrar perícias judiciais ambientais que se utilizaram das geotecnologias, porém, na maioria das vezes, os laudos periciais não documentam de forma adequada os dados e os métodos adotados, nem tampouco exploram as diversas possibilidades de emprego de softwares, imagens de satélites, e dados espaciais disponíveis para a finalidade. Outro problema recorrente se encontra no uso indiscriminado de geotecnologias e dados sem adoção de procedimentos metodológicos adequados para extração de informações e sem conhecer seu real limite de utilização. Cabe aqui como exemplo, a extração de informações geométricas (distâncias, áreas, perímetros e volumes) de objetos de análise pericial a partir de imagens orbitais e de aerolevantamentos cuja característica não são adequadas a atividade fim, como o emprego da plataforma Google Earth ou dados oriundos de drones sem tratamento fotogramétrico.

Considerando esses problemas, a manipulação desses recursos demanda certos cuidados, tanto pelas suas limitações inerentes quanto pela possibilidade de aplicação de tratamento inadequado aos dados, o que pode gerar distorções e comprometer a qualidade do produto cartográfico final. Em razão disso, tornase imprescindível apresentar e discutir alguns protocolos de utilização das geotecnologias em perícia ambiental.

\section{Seleção da área de estudo}

A seleção da área de estudo traduz uma etapa vital para o objetivo proposto na pesquisa e sua importância se justifica pela natureza da investigação, a qual se propôs a avaliar a aplicabilidade de geotecnologias em prol da melhoria da eficiência, da qualidade e do alcance das ações de perícia ambiental. O entorno de um reservatório de abastecimento de água na periferia urbana de uma região metropolitana concentra uma ampla diversidade de problemas legais, frutos da pressão pelo crescimento urbano não planejado sobre áreas de proteção ambiental e estratégicas. Os exemplos analisados revelam situações cotidianas para a perícia ambiental, em função das quais a avaliação do emprego de geotecnologias se faz necessária. A realidade legal e ambiental da área de estudo é similar a de outras áreas no entorno de reservatórios de abastecimento de água, o que permite a replicabilidade desse trabalho.

A escolha da área de estudo ocorreu com base nas seguintes premissas: (1) existência de base cartográfica de qualidade e confiável; (2) existência de dano ambiental observável remotamente, para avaliar o uso de imagens orbitais e aéreas na caracterização e na qualificação de danos ambientais ou de intervenção antrópica em áreas protegidas; (3) representatividade no que se refere à complexidade da perícia; e (4) importância ambiental da área de estudo.

\section{Definição dos estudos de caso}

Os casos estudados tratam de intervenções antrópicas observáveis in loco ou de forma remota por imagens aéreas, sendo que as intervenções qualificam dano ao meio ambiente segundo a legislação ambiental vigente. A definição dos locais examinados se deu a partir das informações relativas à área de 
estudo (imagens de satélites, dados cartográficos, restrições impostas pela legislação ambiental, dentre outras), por meio das quais foram escolhidas intervenções representativas no que tange à complexidade pericial e o impacto dessas intervenções sobre essa área.

\section{Abordagem qualitativa (análise visual)}

A abordagem qualitativa da pesquisa se deu por meio de análise visual de imagens de satélite disponibilizadas no software Google Earth Pro. Foram considerados fatores como a disponibilidade de cenas cobrindo a região de interesse nas datas compatíveis com a necessidade da análise pericial, a qualidade visual do objeto/feição geográfica observado na cena e a usabilidade dos dados.

A disponibilidade e a qualidade visual da sequência histórica de imagens do referido software permitem a análise multitemporal das imagens, processo que permite ao perito detectar remotamente a época em que ocorreu o dano ambiental observado. Essa estratégia, embora caracterize uma análise preliminar, deve ser isenta que métricas quantitativas. Todavia, esse ferramental capaz encontrar a data aproximada das mudanças indicativas de danos ambientais é de vital importância para o planejamento das ações periciais in loco e remotas, como por exemplo, parametrizar no espaço e no tempo a aquisição de imagens geometricamente aptas a fornecer medidas para quantificar a irregularidade causadora do dano.

\section{Abordagem quantitativa (geoprocessamento)}

A abordagem quantitativa recorre ao emprego de técnicas de geoprocessamento de forma a analisar e mensurar os danos ambientais das áreas examinadas como estudo de caso. O processo utiliza fotografias aéreas e ferramentas de Processamento Digital de Imagens (PDI) para determinar e medir remotamente as irregularidades que caracterizam os danos ambientais. $O$ geoprocessamento é também empregado para classificação da cobertura e uso da terra e avaliação das métricas da paisagem.

\section{Mensuração de irregularidades por Sensoriamento Remoto}

A mensuração das irregularidades foi desenvolvida tomando como base uma ortofoto cedida pela Prefeitura de Contagem/MG, correspondente a escala 1:1.000 e processada a partir de umas imagens aéreas tomadas em 2017. A processo utilizou como ferramenta o software QGIS 3.8, onde foram realizadas mensurações remotas de danos ambientais, utilizando técnicas de PDI. As irregularidades que se caracterizavam como danos foram devidamente localizados e mensurados a partir da referida ortofoto, que possui resolução espacial de $10 \mathrm{~cm}$ e rigor cartográfico atestado por relatório de voo.

\section{Análise das métricas da paisagem}

Outra etapa do estudo consistiu em analisar quantitativamente as mudanças da paisagem no que diz em respeito à transição, ao aumento e à diminuição das áreas de cada classe, para as quais foram utilizadas imagens de cobertura e de uso do solo da plataforma MapBiomas. O processamento dos dados ocorreu por meio do software Dinamica EGO. O processo é caracterizado pela análise do padrão das classes de cobertura 
e uso do solo quanto a fragmentação, conurbação, área e parâmetros de geometria dessas classes. O processo revela através de índices a situação de ocupação da superfície e, se repetido para outras datas, subsidia o entendimento da dinâmica das mudanças como padrão das transformações, tendências espaciais das transformações e velocidade com a qual estas ocorrem.

\section{Documentação da pesquisa}

A documentação da pesquisa ordena e sintetiza a comparação dos dados e dos métodos de emprego para criação do protocolo de geotecnologia em perícias ambientais, encampando os objetivos da presente investigação.

\section{RESULTADOS}

\section{Levantamento das informações da ação pericial e dos dados geográficos}

Escolhida a área de estudo, estabeleceu-se uma base de dados georreferenciados com informações indicativas de sua caracterização (imagens de satélites, ortofotos, dados cartográficos em geral, dados de uso e cobertura do solo, restrições impostas pela legislação ambiental, dentre outras), extraídas das plataformas IDE-Sisema, MapBiomas, Geo Catálogo MMA, Google Earth e de dados oficiais cedidos pela prefeitura do Município Contagem/MG. De posse dessas informações efetuou-se uma análise preliminar da área para identificação de potenciais irregularidades e seleção dos casos a serem analisados.

O passo seguinte foi escolher os pontos que foram revisitados. Conforme mencionado anteriormente, a área de estudo escolhida foi objeto de fiscalização. No total, foram fiscalizados 29 empreendimentos e propriedades, sendo lavrados 29 autos de fiscalização, 45 autos de infração e coletadas as coordenadas geográficas, com receptores GNSS de navegação, de todos os pontos fiscalizados. Para o desenvolvimento do estudo, utilizaram-se informações de localização e de irregularidade apontadas nos autos de fiscalização e de infração visando, com base no processo judicial, a escolha dos casos a serem estudados. No Quadro 2 são apresentadas as irregularidades dos estudos de caso escolhidos, bem como seu detalhamento. Cabe mencionar, no entanto, que optamos pela supressão das coordenadas geográficas dos pontos, de modo a preservar a localização dos empreendimentos fiscalizados.

Quadro 2: Irregularidades apontadas para os estudos de caso escolhidos.

\begin{tabular}{|l|l|l|}
\hline \multicolumn{1}{|c|}{$\begin{array}{c}\text { Estudo de } \\
\text { Caso }\end{array}$} & \multicolumn{1}{c|}{ Irregularidade Constatada } & \multicolumn{1}{c|}{ Detalhamento } \\
\hline 01 & Parcelamento de solo irregular em área rural & Supressão de vegetação. \\
\hline 02 & & Em curso d'água natural. \\
\cline { 1 - 1 } 03 & Intervenção em área de preservação permanente & $\begin{array}{l}\text { Em reservatório artificial (destinado ao abastecimento } \\
\text { público). }\end{array}$ \\
04 & (APP) & $\begin{array}{l}\text { Em reservatório artificial (destinado ao abastecimento } \\
\text { público). }\end{array}$ \\
\hline
\end{tabular}

Cabe aqui ressaltar que, independente da fiscalização, os casos abordados neste estudo tratam de fatos reais. Informações referentes ao imóvel passíveis de identificação do mesmo ou do proprietário não fizeram parte do presente estudo, que tem como intuito exemplificar o uso da metodologia. Também, é 
importante frisar que não foram realizadas análises de eventuais licenças ambientais ou do histórico de ocupação dessas áreas, o que poderia legitimar as situações encontradas perante a legislação vigente. Inclusive, cumpre observar que, em alguns casos, seria necessária a elaboração de Plano Ambiental de Conservação e Uso do Entorno de Reservatório Artificial (PACUERA) para a utilização adequada e efetiva da área em questão.

Após a escolha dos estudos de caso, levantaram-se, pontualmente, informações relativas às áreas, no intuito de tornar os trabalhos de campo mais objetivos e eficientes. Por meio do o software QGIS 3.8, os dados foram preparados e as informações, extraídas. Os produtos cartográficos deram suporte à vistoria in loco (diligência pericial), com o auxílio de receptores GPS, trena digital, câmera fotográfica e tablet, para registro dos dados e anotações.

\section{Análise qualitativa e quantitativa do emprego de geotecnologia em perícia ambiental}

É importante mencionar que, para esta pesquisa, três diferentes análises foram realizadas em sequência: [1] análise qualitativa preliminar e multitemporal resultante da inspeção visual remota; [2] análise quantitativa resultante da mensuração de irregularidades; e [3] análise quantitativa resultante de métricas da paisagem. Os resultados obtidos em cada exemplo de utilização das geotecnologias em perícias encontram-se apresentados e discutidos a seguir, a começar pela análise de sequência histórica de imagens do Google Earth, passando pelas imagens orbitais Rapideye, pela ortofoto e concluindo com análise quantitativa de perda e ganho de área das imagens classificadas da plataforma Mapbiomas.

\section{Análise multitemporal}

$\mathrm{Na}$ avaliação da qualidade e da usabilidade das imagens do Google Earth foi utilizada uma sequência histórica de imagens, analisando a disponibilidade e a qualidade visual das mesmas. A análise empírica observou que, para área de estudo, a plataforma do Google Earth disponibilizou cerca de 100 imagens referentes ao período de 2012 a 2019.

Como se observa na Figura 3, as imagens da plataforma Google Earth permitiram identificar a ocorrência de um parcelamento de solo - com supressão de vegetação - cuja data provável de início foi o ano de 2011. A sequência cronológica de imagens permitiu inferir que o maior acréscimo de área desmatada ocorreu entre os anos de 2014 e 2015. Percebe-se, ainda, que a sequência histórica de imagens nos permite acompanhar a evolução do dano ambiental nos diferentes anos, comprovando que o desmatamento está aumentado com o passar do tempo. Essa análise visual, embora qualitativa, reforça a compreensão espaçotemporal do fenômeno causa ou consequência do dano ambiental a ser investigado.

Observou-se que, embora as imagens apresentassem diferenças no padrão de cor, brilho e contraste, fruto de aquisições em épocas distintas, sob condições atmosféricas e de luminosidade distintas e por sensores distintos, a qualidade visual no geral foi satisfatória para a identificação visual de ocorrência do dano ambiental. Isso significa que, como estão disponíveis diversas imagens de boa qualidade visual, existe uma maior probabilidade de se encontrar imagens próximas à data de ocorrência do evento em exame. É 
importante ressaltar, contudo, que essas imagens trazem com elas distorções as quais inviabilizam sua utilização para fins cartográficos.

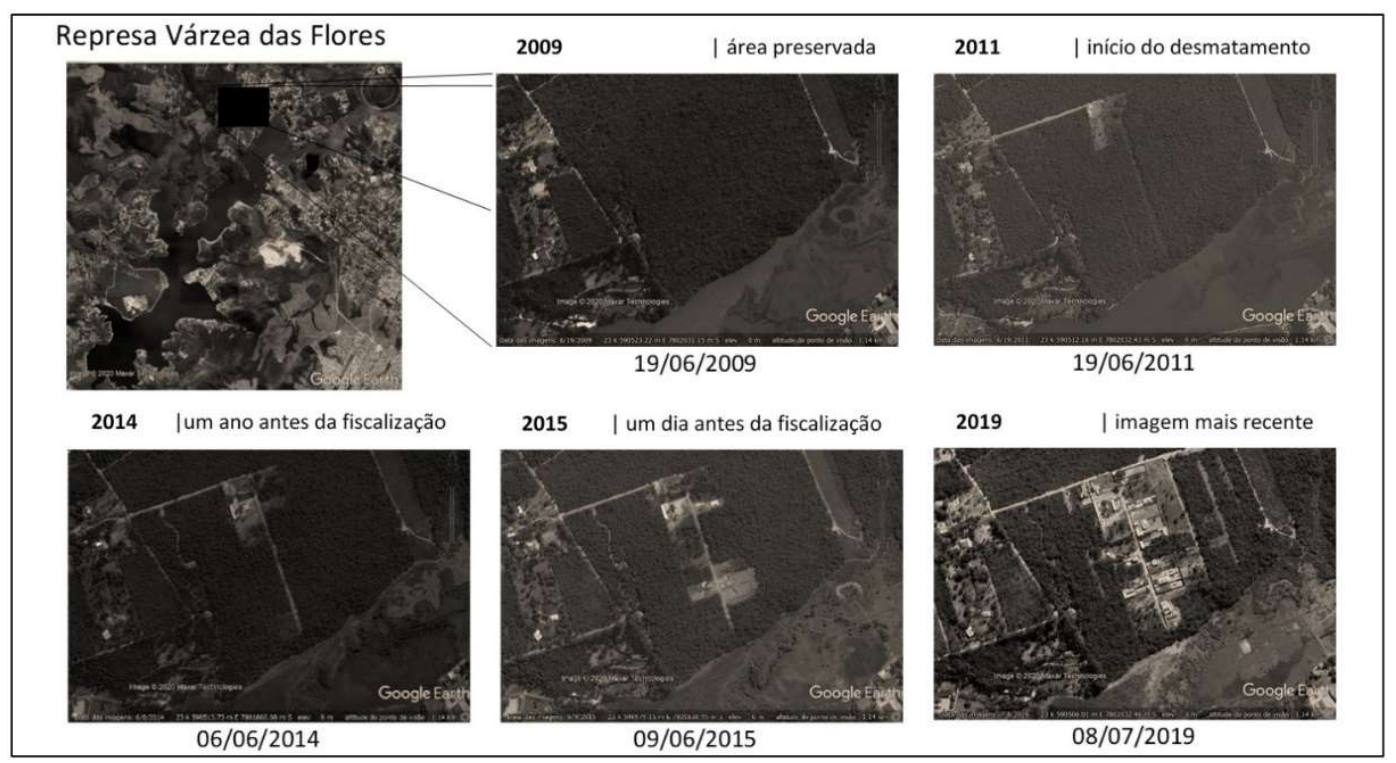

Figura 3: Sequência histórica de imagens de área fiscalizada (loteamento irregular).

\section{Mensuração de irregularidades}

O processo de mensuração das irregularidades é aplicado pontualmente para as feições, objetos ou fenômenos no terreno elencados como irregulares ou sujeitos à irregularidade ambiental. O processo emprega dados e técnicas específicas de sensoriamento remoto que normalmente exigem considerável memória e capacidade computacional. Neste estudo foram avaliadas duas fontes que traduzem na prática duas alternativas comuns e relativamente acessíveis para trabalhos em perícia ambiental: imagens orbitais multiespectrais e fotografias aéreas ortorretificadas.

\section{Imagens Orbitais Multispectrais}

Foram utilizadas imagens do Rapideye ${ }^{4}$ que é um sistema alemão que opera 5 satélites lançados conjuntamente, e geram imagens multispectrais coloridas com resolução espacial de 5 metros. Na avaliação de sua qualidade e usabilidade à perícia ambiental, foi utilizado um mosaico com duas cenas. As imagens possuem cinco faixas espectrais: azul, verde, vermelho, vermelho limítrofe (red-edge) e infravermelho próximo, o que permitiu diferentes composições coloridas. Optou-se pelo uso dessas imagens pelo fato de serem imagens gratuitas e porque a área de estudo foi objeto de fiscalização em 2015, época na qual o satélite ainda estava em operação.

Observando as informações dispostas nos metadados da imagem e analisando a aderência geométrica da imagem à base cartográfica, percebeu-se que as imagens Rapideye são compatíveis a escala

\footnotetext{
${ }^{4}$ A constelação RapidEye é formada por 5 satélites multiespectrais, lançados em agosto de 2008 . O controle é feito por empresa privada alemã. Possui resolução espacial de $5 \mathrm{~m}$, radiométrica de 12 bits e 5 faixas espectrais. O diferencial oferecido pela RapidEye é a capacidade de revisitar diariamente qualquer ponto da terra, fazendo com que ele possa ser utilizado para monitoramento de eventos em agricultura, cartografia, florestas e em outros que necessitem de uma atualização de dados mais rápida. Para maiores informações, consulte: DLR. Deutsches Zentrum für Luft-und Raumfahrt German Aerospace Center. German satellite fleet RapidEye is launched. News Archive, 2008.
} 
cartográfica 1:50.000. Em síntese, mesmo a imagem sendo de média resolução espacial, sua escala de utilização recomendada não é adequada para mensurar pequenas áreas e/ou objetos. Esse cuidado foi necessário posto que nesta etapa da análise o objetivo é a realização de medidas que possam ser usadas como elementos de prova da perícia ambiental. Cabe ressaltar que a área de estudo possui grande variedade de feições e que os principais danos ambientais observados se referem a intervenções construtivas de pequeno porte. Logo, a identificação imprecisa das medidas compromete substancialmente o exame remoto, e esse foi um fator decisivo para descaracterizar o emprego de imagens de média resolução como a Rapideye para a medição da área desmatada apontada na etapa de identificação e análise qualitativa. Contudo, essas imagens são indicadas para mensurar grandes áreas.

\section{Fotografias Aéreas Ortorretificadas}

Nesta etapa foram empregadas ortofotos digitais ${ }^{5}$ cedidas pela prefeitura municipal de Contagem/MG. Para a avaliação da qualidade e da usabilidade dessas ortofotos, a pesquisa se valeu de um recorte de parte da APA de Vargem das Flores. As ortofotos foram carregadas na plataforma QGIS e sobrepostas às demais camadas de informação do banco de dados, o que permitiu analisar três casos de intervenção indevida em Áreas de Preservação Permanente (APP) de proteção e de conservação dos recursos hídricos e dos ecossistemas aquáticos, um de curso d'água natural e dois de reservatório artificial destinado ao abastecimento público.

Como pode ser visto na Figura 4, as edificações examinadas estão parcialmente ou totalmente inseridas na faixa marginal de 30 metros de afastamento do curso d'água ou da linha de cota máxima da represa, área considerada como APP. A referida representação é suficiente para comprovar eventuais danos ambientais pois, conforme informações técnicas do aerolevantamento e da ortofoto, a imagem apresenta elemento de resolução espacial de $10 \mathrm{~cm}$ no terreno e alto rigor cartográfico atestado a priori que garante a qualidade posicional da análise.

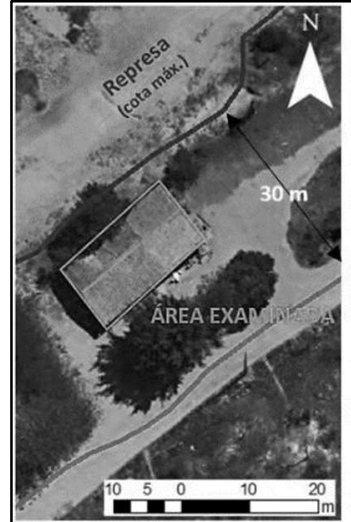

(a)

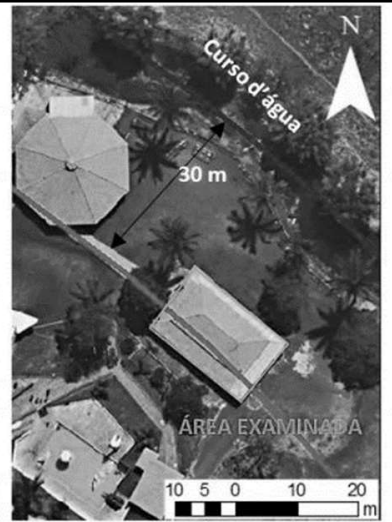

(b)

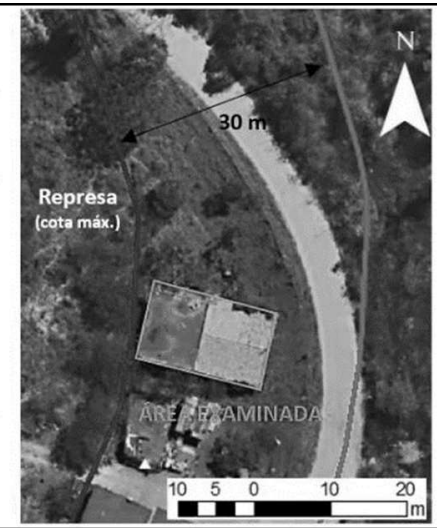

(c)

Figura 4: Áreas examinadas com ortofoto.

\footnotetext{
${ }^{5}$ Levantamento aerofotogramétrico realizado sob demanda pela Prefeitura de Contagem/MG. Os voos foram realizados em 2017 e a ortofoto possui resolução espacial de $0,10 \mathrm{~m}$ e 3 faixas espectrais. Os dados foram disponibilizados em mídia física pela secretaria municipal de Planejamento (SEPLAN).
} 


\section{Análise das Métricas da Paisagem}

A análise de métricas da paisagem não é realizada de forma pontual, ou seja, não tem como alvo um objeto/feição supostamente irregular, mas sim aplicada a região para retratar de forma quantitativa o padrão da distribuição das diversas tipologias de cobertura e uso do solo na área. Na avaliação de sua usabilidade utilizaram-se mapas temáticos produzidos pelo Projeto MapBiomas. Os mapas, em formato matricial, corresponderam a dois anos diferentes, o que possibilitou não somente o cálculo e a análise das métricas por ano, mas também a quantificação das mudanças da paisagem. Para o estudo, foi adotado um período de 20 anos, sendo que os mapas temáticos utilizados foram produzidos a partir de imagens datadas de 1996 2016.

Nesse processo, são calculadas as transições de tipologias de cobertura e uso do solo no período estudado e o aumento e diminuição das áreas de cada classe. Todo o cálculo, incluindo a construção da matriz de transição, foi realizado no software Dinamica EGO (SOARES et al., 2009), que assim como os demais sistemas utilizados nessa pesquisa, é também uma ferramenta gratuita. Ao avaliar o produto, observa-se que, ao longo dos 20 anos analisados, de 1996 (10 anos antes da criação da APA) a 2016 (10 anos depois da criação da APA), a paisagem da APA de Vargem das Flores encontra-se significativamente alterada. A Figura 5 ilustra lado a lado os mapas de cobertura do solo para as duas datas.

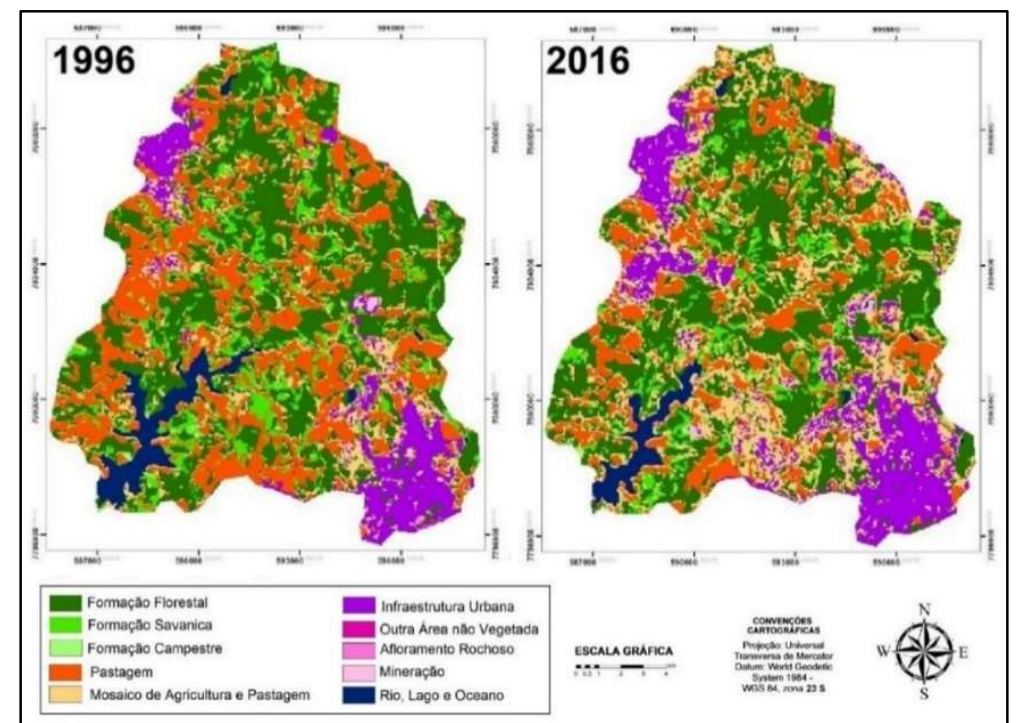

Figura 5: Uso e cobertura do solo para a área de estudo em 1996 e 2016.

Observa-se que a classe 'Formação Florestal' predomina e que sua área permanece estável. No entanto, conforme se verifica na TAB. 1 e TAB. 2, houve forte transição dessa classe nos dois anos analisados, indicando que cerca de 1.000 ha (25\%) da classe 'Formação Florestal' mudou de lugar, ou seja, não houve preservação e sim desmatamento de algumas áreas e regeneração de floresta em outras.

A manutenção da taxa de área florestal ao longo do período como uma métrica de conservação pode não ser sensível ao entendimento do fenômeno. Uma simples analogia entre as áreas totais de cobertura florestal para as duas datas revelaria que a área florestal no entorno da APA está sendo preservada, o que de fato não reflete o ocorrido. O exemplo aqui tomado considerando a área de cobertura florestal no 
entorno do reservatório de abastecimento de água é discutido em (SCANAVACA JUNIOR, 2011), posto que as florestas são importantes devido a vários fatores, sobretudo em relação aos recursos hídricos, pois interceptam a água das chuvas, reduzindo o risco de erosão, aumentam a capacidade de infiltração da água no solo, tornando-o mais poroso, e contribuem para a estabilidade do sistema ou microssistema

Tabela 1: Área das classes em hectare e percentual para os anos 1996 e 2016.

\begin{tabular}{|c|c|c|c|c|c|c|c|c|}
\hline \multirow{2}{*}{ Classe/Ano } & \multicolumn{2}{|c|}{1996} & \multicolumn{2}{|c|}{2016} & \multicolumn{2}{|c|}{ Transição da Classe (ha) } & \multicolumn{2}{|c|}{ Transição Líquida (ha) } \\
\hline & Área (ha) & $\mathrm{Em} \%$ & Área (ha) & $\mathrm{Em} \%$ & Perda & Ganho & Perda & Ganho \\
\hline Formação Florestal & $4.336,11$ & $35,34 \%$ & $4.281,59$ & $34,90 \%$ & 1096,15 & 1041,63 & $-54,51$ & \\
\hline Formação Savânica & $1.417,19$ & $11,55 \%$ & 945,45 & $7,71 \%$ & 985,16 & 513,42 & $-471,74$ & \\
\hline Formação Campestre & 32,06 & $0,26 \%$ & 34,78 & $0,28 \%$ & 26,36 & 29,09 & & 2,72 \\
\hline Pastagem & $3.454,11$ & $28,15 \%$ & $2.092,02$ & $17,05 \%$ & $1.836,97$ & 474,89 & $-1.362,08$ & \\
\hline Mosaico de Agricultura e Pastagem & $1.376,62$ & $11,22 \%$ & $2.811,93$ & $22,92 \%$ & 687,16 & 2122,47 & & $1.435,31$ \\
\hline Infraestrutura Urbana & $1.086,03$ & $8,85 \%$ & $1.751,84$ & $14,28 \%$ & 105,97 & 771,78 & & 665,82 \\
\hline Afloramento Rochoso & 33,93 & $0,28 \%$ & 2,81 & $0,02 \%$ & 33,85 & 2,72 & $-31,13$ & \\
\hline Mineração & 15,65 & $0,13 \%$ & 12,76 & $0,10 \%$ & 10,63 & 7,74 & $-2,89$ & \\
\hline Rio, Lago e Oceano & 517,07 & $4,21 \%$ & 335,59 & $2,74 \%$ & 190,84 & 9,35 & $-181,49$ & \\
\hline TOTAL & $12.268,77$ & $100,00 \%$ & $12.268,77$ & $100,00 \%$ & 4973,09 & 4973,09 & $-2.103,84$ & $2.103,84$ \\
\hline
\end{tabular}

Tabela 2: Matriz de transição (software Dinamica EGO). Perda e ganho de área entre classes em hectares (ha).

\begin{tabular}{|c|c|c|c|c|c|c|c|c|c|c|c|}
\hline & & & & & $\longrightarrow$ & $P E R D A(r$ & а) $\longrightarrow$ & & & & \\
\hline & & $\begin{array}{l}\text { Formação } \\
\text { Florestal }\end{array}$ & $\begin{array}{l}\text { Formação } \\
\text { Savânica }\end{array}$ & $\begin{array}{c}\text { Formação } \\
\text { Campestre }\end{array}$ & Pastagem & $\begin{array}{c}\text { Mosaico } \\
\text { Agri. e Past. }\end{array}$ & $\begin{array}{l}\text { Infraestrut. } \\
\text { Urbana }\end{array}$ & $\begin{array}{l}\text { Afloram. } \\
\text { Rochoso }\end{array}$ & Mineração & $\begin{array}{c}\text { Rio, Lago e } \\
\text { Oceano }\end{array}$ & SOMA (Perda) \\
\hline & $\begin{array}{l}\text { Formação } \\
\text { Florestal }\end{array}$ & - & 248,33 & 3,23 & 164,99 & 547,35 & 129,61 & - & 0,60 & 2,04 & 1096,15 \\
\hline & $\begin{array}{l}\text { Formação } \\
\text { Savânica }\end{array}$ & 406,94 & - & 6,46 & 138,45 & 372,41 & 55,11 & - & 1,79 & 4,00 & 985,16 \\
\hline G & $\begin{array}{l}\text { Formação } \\
\text { Campestre }\end{array}$ & 0,26 & 4,76 & - & 1,87 & 14,80 & 2,47 & - & 2,21 & - & 26,36 \\
\hline $\begin{array}{l}\mathrm{A} \\
\mathrm{N}\end{array}$ & Pastagem & 349,28 & 151,89 & 7,91 & - & 999,87 & 327,42 & - & 0,26 & 0,34 & 1836,97 \\
\hline $\begin{array}{l}\mathrm{H} \\
\mathrm{O}\end{array}$ & $\begin{array}{c}\text { Mosaico } \\
\text { Agri. e Past. }\end{array}$ & 231,92 & 82,07 & 4,59 & 124,93 & - & 241,87 & - & 0,51 & 1,28 & 687,16 \\
\hline (ha) & $\begin{array}{c}\text { Infraestrut. } \\
\text { Urbana }\end{array}$ & 5,95 & 3,06 & 5,95 & 11,23 & 77,31 & - & - & 2,38 & 0,09 & 105,97 \\
\hline$\downarrow$ & $\begin{array}{l}\text { Afloram. } \\
\text { Rochoso }\end{array}$ & 10,80 & - & - & 3,32 & 11,82 & 7,91 & - & - & - & 33,85 \\
\hline & Mineração & - & - & 0,94 & - & 6,04 & 2,04 & - & - & 1,62 & 10,63 \\
\hline & $\begin{array}{c}\text { Rio, Lago e } \\
\text { Oceano }\end{array}$ & 36,48 & 23,30 & - & 30,11 & 92,87 & 5,36 & 2,72 & - & - & 190,84 \\
\hline & $\begin{array}{c}\text { SOMA } \\
\text { (Ganho) }\end{array}$ & 1041,63 & 513,42 & 29,09 & 474,89 & 2122,47 & 771,78 & 2,72 & 7,74 & 9,35 & \\
\hline
\end{tabular}

Em uma análise quantitativa de perda e ganho de área (TAB. 2), as classes 'Mosaico de Agriculta e Pastagem' e 'Infraestrutura Urbana' foram as que tiveram maior ganho. As que mais perderam área para 'Infraestrutura Urbana' foram 'Pastagem' e 'Mosaico Agricultura e Pastagem'. Em síntese, as áreas mais antropizadas deram lugar à expansão urbana e as classes 'Formação Florestal', 'Formação Savânica' e 'Pastagem' deram lugar à classe 'Mosaico Agricultura e Pastagem', indicando um processo intenso de antropização devido a essa expansão.

De forma análoga, a análise das transições revelou que as classes 'Formação Savânica' e 'Pastagem' tiveram maior perda no período. Houve uma forte transição da 'Formação Savânica' para 'Mosaico de Agricultura e Pastagem' e de 'Pastagem' para 'Mosaico de Agricultura e Pastagem'.

Considerando que a atual urbanização mundial se caracteriza pelo rápido e desordenado crescimento dos grandes centros, em que as consequências são inúmeros problemas de ordem ambiental e 
socioespacial (MARCHIORI, 2018), após a análise quantitativa do espaço geográfico em estudo, foi possível observar que a área em exame, hoje bastante modificada, talvez não suporte o mesmo ritmo de degradação observado entre os anos 1996 e 2016, o que seguramente permite afirmar que a APA de Vargem das Flores necessita de cuidados emergenciais quanto à preservação ambiental.

Embora complexa, se comparada às análises anteriores (qualitativa por inspeção visual e qualitativa por mensuração de distância, área e volume), a análise de métricas da paisagem fornece ao processo judicial base para a caraterização do ambiente em que o objeto da ação judicial está inserido. $O$ entendimento espaço-temporal do fenômeno e das possíveis causa e efeito pode fornecer ao Juízo argumentos para a tomada de decisão mais assertiva.

\section{DISCUSSÃO}

Com relação à área escolhida para o estudo, a fiscalização ambiental de 2015 foi motivada por recorrentes conflitos de uso e ocupação do solo. Nesse contexto, torna-se relevante advertir sobre a importância do reservatório de água como estratégia para o abastecimento da região. Assim, em virtude do rompimento da barragem de rejeitos de mineração da empresa Vale, no município de Brumadinho/MG - que afetou diretamente os pontos de captação de água do Rio Paraopeba -, o reservatório de Várzea da Flores e apenas outros dois - Serra Azul e Rio Manso - passaram a ser as únicas fontes de água para o abastecimento de grande parte da Região Metropolitana de Belo Horizonte.

Quanto ao uso de imagens do Google Earth, cumpre observar que, apesar de a qualidade visual das imagens ser satisfatória, extrair informações geográficas (coordenadas de pontos) e/ou geométricas (distâncias, áreas e perímetros) é temerário e pode comprometer ou colocar em dúvida as conclusões alcançadas. Essas imagens possuem excelente potencial elucidativo em ações de fiscalizações e perícias, se usadas de forma adequada, ou seja, nos moldes em que foram utilizadas - sem a extração de informações geográficas e geométricas -, mostraram-se de grande valia na identificação aproximada da época em que ocorreu determinado dano ambiental. A aplicação dessa metodologia se restringe à disponibilidade de imagens da área examinada, cumprindo salientar que, em algumas regiões, não há disponibilidade de muitas imagens.

No que se refere às imagens Rapideye, essas são de excelente qualidade para mapeamento de áreas rurais de grande extensão e, por se tratarem de imagens ortorretificadas, sua utilização cartográfica e pericial pode ser altamente viável, pois eventuais distorções geométricas foram corrigidas, o que as torna eficientes e precisas na delimitação do reservatório, do desmatamento e dos incêndios florestais de grandes proporções em áreas extensas, com limites bem definidos. Entretanto, em relação os itens analisados neste estudo sua aplicação não se justifica, já que a resolução espacial de $5 \mathrm{~m}$ não é suficiente para individualizar edificações de pequeno porte.

Quanto à ortofoto, os resultados dos testes demonstram que seu uso pericial é altamente satisfatório e confiável, uma vez que não foram observadas diferenças significativas entre as medições in loco e as realizadas remotamente, motivo pelo qual é possível ressaltar seu alto poder para extração de informações. 
Porém, um ponto negativo a ser mencionado é a escassez desse tipo de dado para a grande maioria das cidades devido ao elevado custo de recobrimento aerofotogramétrico, o que dificulta sua atualização periódica (LOCH, 1988).

No que concerne ao uso dos mapas de cobertura e uso do solo do MapBiomas, aliados ao cálculo da matriz de transição do software Dinamica EGO, ponderamos que estudos como este permitem entender com maior clareza as nuances da paisagem examinada. Os resultados, somados a outras informações periciais, certamente permitiriam aos órgãos fiscalizadores (ou ao Poder Judiciário) tomar medidas mais enérgicas e imediatas em favor da preservação do meio ambiente, como decisões liminares. Nesse último caso, a mesma técnica poderia ser usada como ferramenta de gestão, por exemplo, na análise de concessão e de renovação de licenciamento ambiental.

A decisão sobre qual produto é mais adequado para a apuração remota dos danos ambientais envolve diversos fatores, tais como o tipo de dano a ser observado, a resolução espacial, a qualidade posicional, a disponibilidade de imagens para o local e época desejados e os custos. Quanto aos custos, vale lembrar que o Código de Processo Civil (CPC) - Lei no 13.105/2015-, no parágrafo $3^{\circ}$ do artigo 473, prevê que, no desempenho de sua função, o perito judicial e os assistentes técnicos podem se valer de todos os meios necessários, inclusive solicitarem documentos que estejam em poder da parte, de terceiros ou em repartições públicas, ou seja, no que tange aos casos examinados neste estudo, o perito não teria nenhum custo adicional para acessar dados ou softwares, isto é, esta pesquisa é perfeitamente replicável quanto a dados, softwares e procedimentos.

Outro ponto importante é o fato do Juízo poder dispensar a prova pericial quando as partes, na etapa inicial e na etapa de contestações, apresentarem pareceres técnicos ou documentos elucidativos sobre as questões que, de fato, podem ser consideradas suficientes. Desta forma, o emprego de geotecnologias nas fiscalizações ambientais pode prover material de qualidade que permita dispensar a perícia judicial e o deslinde da ação, fazendo com que o processo eventualmente ocorra com maior agilidade.

\section{CONCLUSÕES}

A partir dos estudos realizados e dos resultados encontrados, pode-se chegar às seguintes conclusões: 1) Os danos ambientais observados foram identificados de maneira simples, direta e persuasiva, demonstrando a viabilidade do emprego de geotecnologias no aprimoramento do processo de perícia ambiental; 2) O presente trabalho revelou as lacunas e as principais demandas por soluções de geotecnologia no apoio às atividades de perícia ambiental, contornando, de forma alternativa, os altos custos com o uso imagens privadas e softwares licenciados; 3) Foi desenvolvido um estudo de caso aplicando diferentes soluções de geoprocessamento, sendo analisados e apresentados resultados qualitativos e quantitativos do uso de soluções de geotecnologia no escopo da perícia ambiental. A metodologia procurou reproduzir de forma analítica as soluções adotadas pela perícia ambiental e que ainda não estão apoiadas em protocolos seguros destinados a fiscalização ambiental; 4) Esta pesquisa demonstra os prós e contras das soluções de geotecnologia no escopo da perícia ambiental, detalhando alguns procedimentos, bem como esclarece sua 
importância e eventuais limites de utilização. Os resultados pavimentam caminhos rumo a criação e protocolos e recomendações de uso de dados geográficos e métodos de análise para aprimoramento das ações de perícia ambiental; 5) Quanto às mudanças de paradigma e desafios, cumpre destacar que essa metodologia - que se valeu apenas de imagens, dados e softwares disponíveis gratuitamente - supriu com eficiência as demandas periciais de identificação remota de danos ambientais.

\section{REFERÊNCIAS}

ALVES, R. A. L.; RUSSO, D.. Análise multitemporal de imagens LANDSAT 5 no apoio à confecção de laudo pericial da Polícia Federal sobre desmatamento. In: SIMPÓSIO BRASILEIRO DE SENSORIAMENTO REMOTO, 15. Anais. Curitiba: INPE, 2011. p.2959-2966.

ARAGÃO, F. M.; SANTOS, F. A. S.. Sensoriamento remoto na perícia ambiental do Ministério Público do Estado do Piauí: estudo de caso. Engineering Sciences, Aquidabã, v.2, n.1, p.17-28, 2014.

BENEDET, J. S.; JATAHY, D. C.; LOCH, C.. Perícia Ambiental e Cadastro Técnico Multifinalitário. In: CONGRESSO BRASILEIRO DE CADASTRO TÉCNICO MULTIFINALITÁRIO, 12. Anais. Florianópolis: COBRAC, 2016.

BOEIRA, A. S.; BERNINI, H.; CARNEIRO, A. S.; SILVA, D. T.. Uso de geoprocessamento como ferramenta para perícia ambiental de uma área atingida pelo reservatório da Usina Santo Antônio - Rio Madeira. In: SIMPÓSIO BRASILEIRO DE SENSORIAMENTO REMOTO, 17. Anais. João Pessoa: SBSR, 2015. p.6057-6063.

BRILIS, G. M.; GERLACH, C. L.; VAN WAASBERGEN, R. J. Remote sensing tools assist in environmental forensics: Part I. Digital tools - traditional methods. Environmental Forensics, Abingdon, v.1, p.63-67, 2000a. DOI: http://doi.org/10.1006/enfo.2000.0009

BRILIS, G. M.; VANWAASBERGEN, R. J.; STOKELY, P. M.; GERLACH, C. L.. Remote sensing tools assist in environmental forensics: Part II. Digital tools. Environmental Forensics, Abingdon, v.1, p.1-7, 2000b. DOI: http://doi.org/10.1006/enfo.2000.0009

CALDAS, A. J. F. S.; ROTTA, G. V.; GÓES, E. K.; SCHAMNE, J. A.. Sensoriamento remoto na perícia ambiental da polícia federal. In: SIMPÓSIO BRASILEIRO DE SENSORIAMENTO REMOTO, 14. Anais. Natal: INPE, 2009. p.3621-3628.

GASPARINI, K. A. C.; LYRA, G. B.; FRANCELINO, M. R.; DELGADO, R. C.; OLIVEIRA JUNIOR, J. F.; FACCO, A. G. Técnicas de Geoprocessamento e Sensoriamento Remoto Aplicadas na Identificação de Conflitos do Uso da Terra em Seropédica/RJ. Revista Floresta e Ambiente, Seropédica, v.20, n.3, p.296-306, 2013.
IBGE. Instituto Brasileiro de Geografia e Estatística. Introdução ao Processamento Digital de Imagens. Manuais Técnicos em Geociências. Rio de Janeiro: IBGE, 2001.

LIMA, C. A. F.. Correções Geométricas para a Utilização de Imagens em Perícias Criminais Ambientais. Dissertação (Mestrado em Perícias Criminais Ambientais) - Universidade Federal de Santa Catarina, Florianópolis, 2013.

LOCH, C.. Monitoramento global integrado de propriedades rurais a nível municipal, utilizando técnicas de sensoriamento remoto. Tese (Doutorado em Ciência Florestal) - Universidade Federal do Paraná, Curitiba, 1988.

MARCHIORI, L. M.; SARTORI, A. A. C.; OLMEDO, J. P.; GUERREIRO, S. F.. Dinâmica espaço-temporal da expansão urbana de Bauru/SP. Revista Ibero Americana de Ciências Ambientais, Aracaju, v.9, n.3, p.354-364, 2018. DOI: http://doi.org/10.6008/CBPC2179-6858.2018.003.0028

NICOLETTI, E. A. M.; FERREIRA, R. L.. Geotecnologias Aplicadas à Perícia Ambiental. Caderno Meio Ambiente e Sustentabilidade, Curitiba, v.6, n.4, p.37-58, 2015.

SCANAVACA JUNIOR, L.. A importância da floresta para o meio ambiente. Embrapa Meio Ambiente, Natureza e Arte, Brumadinho, v.5, n.29, p.2, 2011.

SILVA, R. M.; INOCENCIO, L. C.; REIS, B. S.; SOARES, G.; KIRSTEN, E.. Fotos digitais obtidas com o uso de VANT para o mapeamento de áreas verdes do Campus da Unisinos em São Leopoldo: análise da exatidão posicional, utilizando o Software GEOPEC. In: SIMPÓSIO BRASILEIRO DE SENSORIAMENTO REMOTO, 17. Anais. João Pessoa: SBSR, 2015. p.6281-6289.

SILVA, C. C. O. A.; BARBOSA, J. B. M.. Utilização da ferramenta sensoriamento remoto para diagnóstico de impactos ambientais. Revista Tecnologia \& Informação, Natal, v.1, p.21-32, 2013.

SOARES FILHO, B. S.; RODRIGUES, H. O.; COSTA, W. L.. Modelagem de Dinâmica Ambiental com Dinamica EGO. Guia prático do Dinâmica EGO. Belo Horizonte: CSR-UFMG, 2009.

A CBPC - Companhia Brasileira de Produção Científica (CNPJ: 11.221.422/0001-03) detém os direitos materiais desta publicação. Os direitos referem-se à publicação do trabalho em qualquer parte do mundo, incluindo os direitos às renovações, expansões e disseminações da contribuição, bem como outros direitos subsidiários. Todos os trabalhos publicados eletronicamente poderão posteriormente ser publicados em coletâneas impressas sob coordenação da Sustenere Publishing, da Companhia Brasileira de Produção Científica e seus parceiros autorizados. Os (as) autores (as) preservam os direitos autorais, mas não têm permissão para a publicação da contribuição em outro meio, impresso ou digital, em português ou em tradução. 